\title{
In vitro Pharmaceutical Equivalence Study of Three Brands of Atenolol Tablets Available in Bangladesh
}

\author{
Rehana Begum ${ }^{1}$, Md. Zakir Sultan², J akir Ahmed Chowdhury ${ }^{3}$ \\ and Md. Shah Amran ${ }^{1}$ \\ ${ }^{1}$ Department of Pharmaceutical Chemistry, Faculty of Pharmacy, University of Dhaka \\ Dhaka-1000, Bangladesh \\ ${ }^{2}$ Centre for Advanced Research in Sciences, University of Dhaka, Dhaka-1000, Bangladesh \\ ${ }^{3}$ Department of Pharmaceutical Technology, Faculty of Pharmacy, University of Dhaka \\ Dhaka-1000, Bangladesh
}

(Received: September 24, 2018; Accepted: February 21, 2019; Published (Web): April 01, 2019)

\begin{abstract}
The aim of the present work was to assess the pharmaceutical equivalence of three brands of atenolol $(50 \mathrm{mg})$ tablets available in Bangladesh using in vitro dissolution study. The dissolution study was carried out using the paddle apparatus according to the guidelines of United States Pharmacopoeia (USP). The dissolution profiles of three locally manufactured atenolol tablets were determined and compared with the dissolution profile of atenolol tablet from innovator's company. All samples attained more than $85 \%$ dissolution within 10 minutes. Mean dissolution values were employed to estimate difference factor $\left(f_{1}\right)$ and similarity factor $\left(f_{2}\right)$. Difference factor $\left(f_{1}\right)$ and similarity factor $\left(\mathrm{f}_{2}\right)$ were used to assess in vitro bio-equivalency among the three brands. Other general quality assessment parameters such as hardness, friability and disintegration time were also determined. All brands complied with the official specifications for hardness, friability and disintegration time. The study indicated that all brands can be prescribed interchangeably.
\end{abstract}

Key words: Atenolol, pharmaceutical equivalence, in vitro, dissolution.

\section{INTRODUCTION}

Hypertension is the most common cardiovascular disease in the world. The prevalence of hypertension increases with age. About $50 \%$ of people between the ages of 60 to 69 years old have hypertension, and the prevalence is further increased beyond age 70 in USA. ${ }^{1}$ Hypertension is also common in our subcontinent. In India and Bangladesh, an increasing trend of hypertensive disease has been reported. ${ }^{2}$ Elevated arterial pressure causes pathological changes in the vasculature and hypertrophy of the left ventricle. As a consequence, hypertension is the principal cause of stroke, a major risk factor for coronary artery disease and its attendant complications myocardial infarction and

Correspondence to: Md. Shah Amran

Email: amranms@du.ac.bd

Phone: +880178617915; Fax: +88-02-9667222

Dhaka Univ. J. Pharm. Sci. 18(1): 43-48, 2019 (June)

DOI: https://doi.org/10.3329/dujps.v18i1.41426 sudden cardiac death. Hypertension is a major contributor to cardiac failure, renal insufficiency and dissecting aneurysm of the aorta. ${ }^{3}$

The antihypertensive drugs are used to treat hypertension. There are different classes of antihypertensive drugs available all over the world. These drugs lower blood pressure by different mechanisms. The most widely used antihypertensive drugs are the $\beta$-adrenoceptor blockers, the centrally acting drugs, the ACE inhibitors and the angiotensin II receptor antagonists. Atenolol is a $\beta$-adrenoceptor blocker. ${ }^{4}$ Atenolol is widely used as antihypertensive agent. It is widely used because of good patient acceptability and cardio-protective potentiality. This drug is also increasingly used for the treatment of angina pectoris, cardiac arrhythmias and myocardial infraction. ${ }^{5}$ 
The bio-pharmaceutical characteristic of atenolol is described as sparingly soluble in water in British Pharmacopoeia (BP). On the basis of studied biopharmaceutical data, atenolol could be clearly classified into Bio-pharmaceutics Classification System (BCS) Class III. ${ }^{6}$ BCS Class III drugs have high solubility and low permeability. ${ }^{7}$

Pharmaceutical equivalence is the condition in which drug products containing the identical quantity of active ingredient in an identical dosage form, meet all applicable standards of identical strength, quality, purity and potency. The following criteria should be considered in the determination of pharmaceutical equivalence - (i) identical amount of active ingredient(s); (ii) same dosage form or comparable dosage form (e.g. Tablets versus Capsules); (iii) same route of administration. ${ }^{8}$

Determination of pharmaceutical equivalence of tablets can be done by comparing the amount of active ingredient, dissolution time, hardness, friability and disintegration time of the test product against the reference product (innovator product). ${ }^{9}$

In recent years, FDA has placed more emphasis on a dissolution profile comparison in the area of post-approval changes and biowaivers. Under appropriate test conditions, a dissolution profile can characterize the product more precisely than a single point dissolution test. A dissolution profile comparison between pre-change and post-change products for scale-up and post approval change (SUPAC) related changes, or with different strengths helps assure similarity in product performance and signals bioinequivalence. ${ }^{10}$

Atenolol tablets are widely used in Bangladesh due to its effectiveness and affordable price. To the best of our knowledge, no reports are available on the pharmaceutical equivalence of various atenolol tablets manufactured in Bangladesh. The availability of numerous brands of atenolol tablets in drug market of Bangladesh makes physicians in a difficult situation to choice a suitable brand or to use of effective alternative brand.

Hence the present study was set out to assess the in vitro pharmaceutical equivalence of atenolol tablets manufactured in Bangladesh. The purpose of the study was to determine dissolution profiles of locally manufactured atenolol tablets and to compare those profiles graphically with drug from innovator's company (as reference standard). In addition to that the results were evaluated statistically using difference factor $\left(f_{1}\right)$ and similarity factor $\left(f_{2}\right)$. This study would provide a rationale for the interchangeability of the selected brands with the innovator brand.

\section{MATERIALS AND METHODS}

Drugs and chemicals. Standard atenolol was a kind gift from Healthcare Pharmaceuticals Ltd., Gazipur, Bangladesh. Three brands of atenolol (50 $\mathrm{mg}$ ) tablets were purchased from the local market of Dhaka city. They were randomly designated as A, B and C. Tablet Tenormin $50 \mathrm{mg}$ (AstraZeneca, the innovator company) was designated as reference innovator (RI). Chemicals and all other reagents were of analytical grade and were purchased from local suppliers.

Preparation of $0.1 \mathrm{~N}$ acetate buffer, $\mathrm{pH}$ 4.6. $0.1 \mathrm{~N}$ acetate buffer, $\mathrm{pH} 4.6$ was prepared by mixing 44.9 parts $(\mathrm{v} / \mathrm{v})$ of $0.1 \mathrm{~N}$ sodium acetate with 55.1 parts $(\mathrm{v} / \mathrm{v})$ of $0.1 \mathrm{~N}$ acetic acid solution and adjusted with diluted acetic acid to a $\mathrm{pH}$ of 4.6 .

Preparation of stock solution of atenolol. A stock solution $(100 \mathrm{~mL})$ of $50 \mu \mathrm{g} / \mathrm{mL}$ was prepared by dissolving $0.05 \mathrm{~g}$ of atenolol in $0.1 \mathrm{~N}$ acetate buffer, $\mathrm{pH} 4.6$ and made up to the mark volume with the same solvent. Then $10 \mathrm{~mL}$ from this was diluted with $0.1 \mathrm{~N}$ acetate buffer at $\mathrm{pH} 4.6$ and finally the volume was adjusted up to $100 \mathrm{~mL}$ with the same solvent. The resulting solution is called stock solution of $50 \mu \mathrm{g} / \mathrm{mL}$. The stock solution was then diluted to the desired strength by $0.1 \mathrm{~N}$ acetate buffer at $\mathrm{pH} 4.6$.

Preparation of calibration curve. Serial diluted solutions of $5.0,7.5,10.0,12.5,15.0 \mu \mathrm{g} / \mathrm{mL}$ of atenolol were prepared from the stock solution (50 $\mu \mathrm{g} / \mathrm{mL}$ ) with $0.1 \mathrm{~N}$ acetate buffer, $\mathrm{pH}$ 4.6. The absorbances were taken at $218 \mathrm{~nm}$ using a UVVisible spectrophotometer (Model UV-800 Shimadzu, Japan). A plot of absorbance versus 
concentration of atenolol was made from which the regression equation was calculated. ${ }^{11}$

Hardness test. The hardness was determined with an automatic tablet hardness tester (Model HDT-300F, Logan Instrument Corp., USA). Six atenolol tablets were randomly selected from each brand and the pressure at which each tablet crushed was recorded.

Friability test. Twenty atenolol tablets of each brand were weighed and subjected to abrasion by using a friability tester (Model FIB-2S, Logan Instrument Corp., USA) at $25 \mathrm{rev} / \mathrm{min}$ for 4 minutes. The tablets were then weighed and percentage friability was calculated.

Disintegration test. Six atenolol tablets of each brand were used for the test in distilled water with an automatic disintegration tester (Model DST-3, Logan Instrument Corp., USA) employing plastic discs. The disintegration time was taken as the time when no particles remained on the basket of the tester.

Dissolution test. The dissolution test was carried out using a dissolution tester (Model UDT-804, Logan Instrument Corp., USA) according to USP guidelines in 6 replicates for each brand. ${ }^{12}$ The dissolution medium was $900 \mathrm{~mL}$ of $0.1 \mathrm{~N}$ acetate buffer, pH 4.6 which was maintained at $37^{\circ} \pm 0.5^{\circ} \mathrm{C}$. The dissolution tester was operated at $50 \mathrm{rpm}$. In all the experiments, $5 \mathrm{~mL}$ of dissolution sample was withdrawn at 5, 10, 15, 30 and 45 minutes and replaced with equal volume of $0.1 \mathrm{~N}$ acetate buffer, $\mathrm{pH} 4.6$ to maintain sink condition. Samples were filtered, diluted and the absorbences were taken at $218 \mathrm{~nm}$ using spectrophotometer where $0.1 \mathrm{~N}$ acetate buffer, pH 4.6 used as blank. The concentrations of samples were determined from the calibration curve of pure atenolol. The percent dissolutions were computed. The data were tailored and computed the means.

Dissolution profile comparison using graph. The percent dissolutions of the samples and reference innovator were graphed versus time.

Determination of $50 \%$ and $90 \%$ dissolution. The time required for $50 \%$ dissolution $\left(\mathrm{T}_{50 \%}\right)$ and
90\% dissolution $\left(\mathrm{T}_{90 \%}\right)$ were determined as they are used as good indicators for dissolution. ${ }^{13}$

Dissolution profile comparison using difference factor and similarity factor. A model independent mathematical approach was used to compare the dissolution profiles of the samples and the reference product using two factors, difference factor $\left(f_{1}\right)$ and similarity factor $\left(f_{2}\right)$. Mean dissolution values were employed to estimate difference factor $\left(f_{1}\right)$ and similarity factor $\left(f_{2}\right)$. The $f_{1}$ values up to 15 $(0-15)$ and $f_{2}$ values greater than 50 (50-100) ensures sameness or equivalence of the test results and the reference product. The following equations were used to calculate difference factor $\left(\mathrm{f}_{1}\right)$ and similarity factor $\left(\mathrm{f}_{2}\right)$ for the studied tablets. ${ }^{14}$

$\mathrm{f}_{1}=\left\{\left[\sum_{t=1} n\left|R_{t}-T_{t}\right|\right] \div\left[\sum_{t=1} n R_{t}\right]\right\} \times 100$

$\mathrm{f}_{2}=50 \mathrm{x} \log \left\{\left[1+(1 / n) \sum_{t=1} r\left(R_{t}-T_{t}\right)^{2}\right]^{-0.5}{ }_{x 100}\right\}$

Where, $\mathrm{n}$ is the number of time points, $\mathrm{R}_{\mathrm{t}}$ is the dissolution value of reference product at time ' $\mathrm{t}$ ' and $T_{t}$ is the dissolution value for the test product at time ' $\mathrm{t}$ '.

Data analysis. The data were express as mean \pm standard deviation $(\mathrm{SD})$.

\section{RESULTS AND DISCUSSION}

Hardness is referred to as non-compendial test. It may influence other quality parameters such as friability and disintegration. The crushing strength about $4 \mathrm{kp}$ is the minimum requirement for a standard tablet. ${ }^{15}$ Tablets of all brands were found to be satisfactory for hardness. Hardness was found to be within 4.55 to $6.13 \mathrm{kp}$ for all brands. The results are shown in table 1.

Friability test is included in the United States Pharmacopoeia. ${ }^{12}$ The standard specification for friability is not more than $1 \%$. It was found to be less than $1 \%$ for each brand of tablets (Table 1 ).

Disintegration times of all the brands were within the limit. The British Pharmacopoeia specifies that uncoated tablets should disintegrate within 15 minutes and film coated tablets within 30 minutes. ${ }^{16}$ All atenolol tablets were disintegrated in less than 2 
minutes (Table 1). The calibration curve has good correlation $\left(r^{2}>0.9999\right)$.

The United States Pharmacopoeia specifies that the amount of atenolol dissolved should not be less than $80 \%$ of the labeled amount in 30 minutes. ${ }^{12}$ All brands complied with the specification. The dissolution mean values of the test products and reference innovator were shown in table 2 .

The results of dissolution studies were presented graphically in figure 1 . All the tested brands released more than $85 \%$ drugs within 10 minutes.

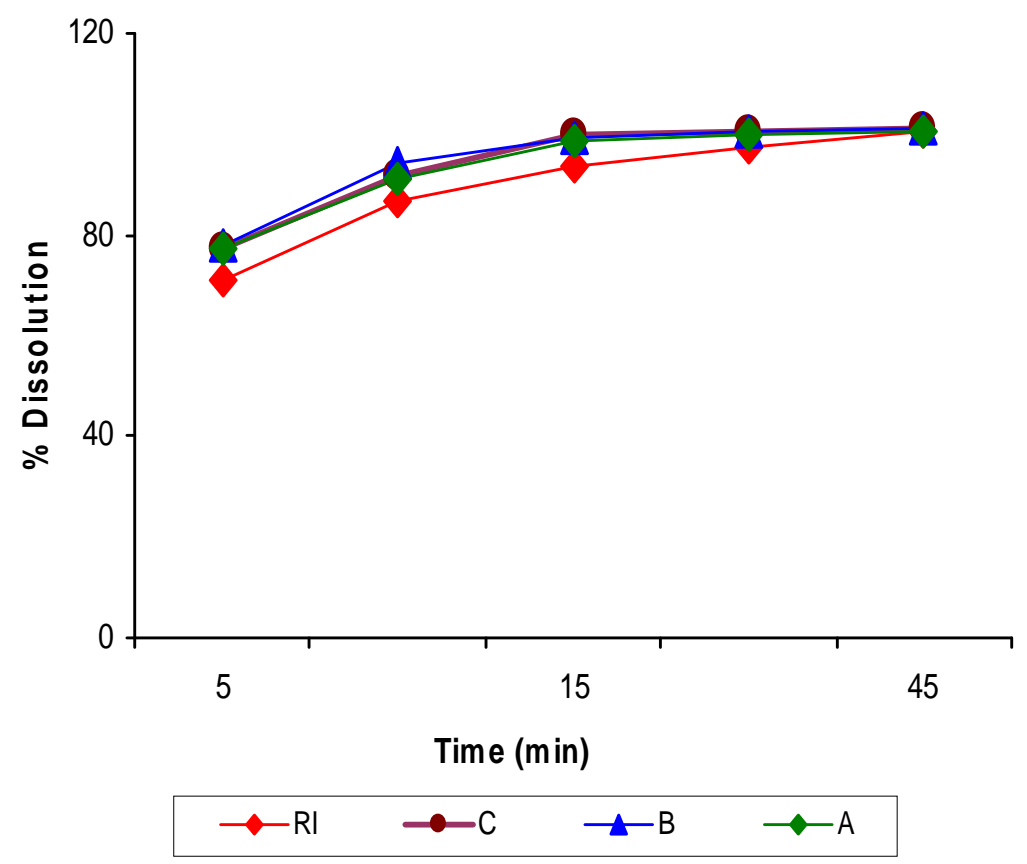

Figure 1. Dissolution profiles of different brands of atenolol tablets.

Table 1. Hardness, \% friability and disintegration time of different brands of atenolol tablets.

\begin{tabular}{cccc}
\hline Formulation & Hardness (kp) & \% Friability & $\begin{array}{c}\text { Disintegration } \\
\text { time (minutes) }\end{array}$ \\
\hline A & $6.13 \pm 0.37$ & 0.097 & $1.23 \pm 0.02$ \\
B & $4.55 \pm 0.15$ & 0.044 & $0.43 \pm 0.01$ \\
C & $5.06 \pm 0.39$ & 0.038 & $1.36 \pm 0.01$ \\
RI & $5.32 \pm 0.50$ & 0.052 & $1.44 \pm 0.02$ \\
\hline
\end{tabular}

Table 2. Mean percent dissolution of different brands of atenolol tablets.

\begin{tabular}{|c|c|c|c|c|}
\hline \multirow[b]{2}{*}{ Time (minutes) } & \multirow[b]{2}{*}{ RI } & \multicolumn{3}{|c|}{ Brands of Tablets } \\
\hline & & A & B & $\mathrm{C}$ \\
\hline 5 & $70.76 \pm 1.89$ & $76.97 \pm 2.91$ & $78.16 \pm 3.33$ & $77.37 \pm 1.64$ \\
\hline 10 & $86.58 \pm 1.48$ & $92.04 \pm 2.66$ & $94.40 \pm 1.27$ & $91.39 \pm 1.34$ \\
\hline 15 & $93.67 \pm 1.47$ & $99.86 \pm 1.21$ & $99.57 \pm 1.19$ & $98.68 \pm 1.55$ \\
\hline 30 & $97.26 \pm 1.43$ & $100.60 \pm 1.9$ & $100.55 \pm 0.77$ & $99.81 \pm 0.97$ \\
\hline 45 & $100.62 \pm 1.22$ & $101.17 \pm 0.45$ & $100.86 \pm 0.67$ & $100.26 \pm 0.75$ \\
\hline
\end{tabular}

RI $=$ Reference Innovator 
Table 3. $\mathbf{T}_{50 \%}, \mathbf{T}_{90 \%}, \mathbf{f}_{1}$ and $\mathbf{f}_{2}$ values of different brands of atenolol tablets.

\begin{tabular}{ccccc}
\hline Formulation & $\mathrm{T}_{50 \%}(\mathrm{~min})$ & $\mathrm{T}_{90 \%}(\mathrm{~min})$ & Difference factor $\left(\mathrm{f}_{1}\right)$ & Similarity factor $\left(\mathrm{f}_{2}\right)$ \\
\hline A & $<5$ & $<10$ & 4.84 & 65.21 \\
B & $<5$ & $<10$ & 5.48 & 61.93 \\
C & $<5$ & $<10$ & 4.14 & 67.08 \\
\hline
\end{tabular}

Similarity factor $\left(\mathrm{f}_{2}\right)$ has been adopted by the Food and Drug administration (FDA) and the European Agency for the Evaluation of Medicinal Products (EMEA) to compare dissolution profiles. ${ }^{14,17}$ Two dissolution profiles are considered similar and bioequivalent, if $\mathrm{f}_{1}$ is between 0 and 15 and $\mathrm{f}_{2}$ is between 50 and $100 .{ }^{14}$ In this study, parameters like $\mathrm{f}_{1}, \mathrm{f}_{2}$ and $\mathrm{T}_{50 \%}, \mathrm{~T}_{90 \%}$ values were derived from the dissolution profiles of the different test brands of atenolol tablets. A $\mathrm{T}_{90 \%}$ of 30 minutes is satisfactory and is an excellent indicator of good dissolution. ${ }^{13}$ Table 3 showed that brands A, B and C had $\mathrm{T}_{50 \%}$ values less than 5 minutes and $\mathrm{T}_{90 \%}$ values less than 10 minutes. Table 3 showed that $\mathrm{f}_{1}, \mathrm{f}_{2}$ values of different test brands in comparison of brand RI and it was observed that brands $A, B$ and $C$ had $f_{1}$ values less than 15 and $\mathrm{f}_{2}$ values more than 50. They, therefore, were similar with brand RI and may be used interchangeably.

\section{CONCLUSION}

The results obtained from the in vitro pharmaceutical equivalence study of three brands of atenolol $(50 \mathrm{mg})$ tablets showed that atenolol tablets of tested brands were equivalent to the brand of reference innovator. It can be inferred that these brands may have similar bioavailability and may be prescribed interchangeably.

\section{ACKNOWLEDGEMENT}

We extend our appreciation to the Healthcare Pharmaceuticals Ltd., Gazipur, Bangladesh for kindly supplying us with standard atenolol.

\section{REFERENCES}

1. Hajjar, I. and Kotchen, T.A. 2003. Trends in prevalence, awareness, treatment and control of hypertension in the United States, 1988-2000. J. Am. Med. Assoc. 290, 199-206.
2. Hypertension study group. 2001. Prevalence, awareness, treatment and control of hypertension among the elderly in Bangladesh and India: a multicentre study. Bull.World Health Org. 79, 490-500.

3. Goodman, L.S., and Gilman, A. 2005. The Pharmaceutical Basis of Therapeutics. $11^{\text {th }}$ ed., McGraw Hill, USA, p. 884.

4. ACE inhibitor. Available from URL: http://en.wikipedia.org/wiki/ACE_inhibitor. Accessed August 9, 2018.

5. Sweetman, S. 2005. Martindale: The Complete Drug Reference. $34^{\text {th }}$ ed., Pharm. Press, London, p. 865.

6. Vogelpoel, H., Welink, J., Amidon, G.L., Junginger, H.E., Midha, K.K., Moeller, H., Olling, M., Shah, V.P. and Barends, D.M. 2004. Biowaiver monographs for immediate release solid oral dosage forms based on biopharmaceutics classification system (BCS) literature data: verapamil hydrochloride, propranolol hydrochloride, and atenolol. $J$. Pharm. Sci. 93, 1945-1956.

7. U.S. Department of Health and Human Services, Food and Drug Administration, Center for Drug Evaluation and Research (CDER). Guidances for industry: Waiver of in vivo bioavailability and bioequivalence studies for immediate-release solid oral dosage forms based on a Biopharmaceutics Classification System, May 2015. Available from URL:http://www.fda.gov/Drugs/GuidanceComplianceRegula toryInformation/Guidances/default.htm. Accessed August 9, 2018.

8. Begum, R., Sultan, M. Z., Rahman. A., Hossain. M. A. and Amran. M. S. 2014. The in vitro pharmaceutical equivalence studies of losartan tablets of different manufacturers available in Bangladesh. Int. J. Pharm. 4, 128-132.

9. Saudi food and drug authority. Guidelines for pharmaceutical equivalence requirements. Available from URL:http://212. 100.220.58/NR/rdonlyres/BBDEAE40-1C55-49C1-B3077 884BA68D217/0/GuidelinesforPharmaceuticalEquivalenceR equirements.pdf. Accessed August 9, 2018.

10. Shah, V.P., Tsong, Y., Sathe, P. and Williams, R.L. 1999. Dissolution profile comparison using similarity factor, $\mathrm{f}_{2}$. Dissolution tech. 6, 15-15.

11. Siraji, F., Azam, Z., Uddin, M.G., Begum, R., Amran, M. S., Islam, J. N. and Hossain, M. A. 2012. In vitro effects of copper (II) and chromium (III) on the protein binding of metronidazole and mebendazole in aqueous media. Int. $J$. Res. Rev. Pharm. App. Sci. 2, 916-929.

12. US Pharmacopoeia 34 National Formulary 29, USP 34/NF 29, 2011. 
13. Lachman, L., Lieberman, H.A. and Kanig, J.L. 1976. The Theory and Practice of Industrial Pharmacy, $2^{\text {nd }}$ edition, pp. 348-349.

14. U.S. Department of Health and Human Services, Food and Drug Administration, Center for Drug Evaluation and Research (CDER), Guidance for industry. Dissolution testing of immediate release solid oral dosage forms, August, 1997. Available from URL:

http://www.fda.gov/downloads/Drugs/GuidanceComplianceRegula toryInformation/Guidances/ucm070237.pdf.Accessed August 9, 2018.
15. Allen, L.V, Popovich, N.G. and Ansel, H.C. 2004. Ansel's Pharmaceutical Dosage Forms and Drug Delivery Systems. $8^{\text {th }}$ ed., p. 236.

16. British Pharmacopoeia (BP), 2001, p. 1183.

17. The European agency for the evaluation of medicinal products (EMEA). Note for guidance on the investigation of bioavailability and bioequivalence. Available from URL: http://www.ema.europa.eu/docs/en_GB/document_library/Sc ientific_guideline/2009/09/WC500003519.pdf. Accessed August 9, 2018. 